\title{
Cuando el cuerpo es música al bailar
} Entrevista a Claudio Villagra

\author{
Alejandro César Grosso Laguna \\ cultura@netcabo.pt \\ Laboratorio para el Estudio de la Experiencia Musical. Facultad de Artes - \\ Universidad Nacional de La Plata. \\ Instituto de Etnomusicologia - Estudos Música e Dança. Departamento de \\ Comunicação e Arte - Universidade de Aveiro.
}

\section{Biografia del entrevistado}

Claudio Villagra nació en 1972 en Buenos Aires, Argentina. Comenzó a aprender tango a los cinco años con su abuelo Héctor Contreras, a quien considera su mentor. Se formó con legendarios bailarines como Juan Aurelio, Juan Carlos Copes, "Virulazo", Antonio Todaro, "Pepito Avellaneda", Gloria y Eduardo Arquimbau, Rodolfo y Gloria Dinzel, Norberto Guichanduc. Bailó con las orquestas de Osvaldo Pugliese, Mariano Mores, Sexteto Sur, El Arranque, Color Tango y el Sexteto Mayor y con los solistas de D’Arienzo. Formó parte del elenco de Tanguera, Tango Seducción, Tango Argentino y fue bailarín principal de la compañía Forever Tango. Actuó en reconocidos teatros de Broadway como el Walter Kerr Theatre y el Marquis Theatre (durante dos años), el Olympia Music Hall de París, el Teatro de Bellas Artes de México, el Teatro Colón y el Teatro Nacional Cervantes. Creó, produjo y coreografió su espectáculo Latin Tango (2003). Ha trabajado con reconocidas bailarinas como Alejandra Martiñan, Guillermina Quiroga, Karina Piazza, Miriam Larici, Romina Levin. Actualmente comparte su trabajo artístico con su compañera, la bailarina Helena Fernández, a quien destaca entre las mejores bailarinas-artistas del tango. Realizó exhibiciones en las principales milongas de Buenos Aires, y fue jurado del Campeonato Mundial de Tango en Buenos Aires. 


\section{Introducción}

Claudio Villagra es un bailarín de tango de reconocida trayectoria nacional e internacional que aprendió con antiguos milongueros ya fallecidos, que ha conseguido dominar tanto el estilo tradicional de la milonga como la performance de escenario.

La entrevista encauza a Villagra a describir los rasgos estilísticos del Tango Tradicional (TT) desde la perspectiva sentida de la experiencia kinestésica y musical de su cuerpo.

El autor desafía al entrevistado a traducir sus sensaciones en términos de nociones y categorías que iluminan algunos aspectos procedimentales del TT que los antiguos milongueros no han sabido verbalizar. Paralelamente, Villagra realiza una retrospectiva de las transformaciones que ha venido sufriendo el TT en los últimos 25 años.

La presente entrevista es parte de un estudio mayor que tiene como objetivo mantener vivo el legado corporal de los antiguos milongueros de los barrios de Villa Urquiza y Saavedra.

\section{Transcripción}

Alejandro Laguna: ¿Qué significa para vos caminar el tango?

Claudio Villagra: Yo te puedo dar mi punto de vista de acuerdo a como me lo enseñaron. El caminar de la calle es importante...es complejo el tema...Se trata de "ser natural". Todos hablamos de que el tango viene del caminar. Es verdad. Pero hay muchos que hablan de un caminar o de un abrazo y no lo aplican a lo que realmente ellos están enseñando. Lo dicen porque es una palabra que queda "de diez". Te lo digo porque yo soy también una persona como vos, estudiosa, que para saber bien lo que estaban enseñando afuera, me inmiscuí "undercover" en las clases y no te puedo decir las cosas que escuché...barbaridades. Pero saqué una conclusión de todo eso para saber. Yo tengo un método que se llama la espi$\mathrm{ral}$, que tiene un mensaje subliminal, que es muy profundo y que se basa en una comunicación con la pareja que hoy no existe. Eso es algo que ya se perdió y por lo que yo vengo luchando hace mucho tiempo: "la gente que baila por que le gusta hacer cosas lindas". El ser virtuoso, el hacer pasos, el hacer buenas secuencias no quiere decir que bailes bien. Esto es muy importante. El caminar de la calle es como una "guía" que vos tenés para efectuar el movimiento. Antiguamente cuando yo era chico mi abuelo me llevaba siempre a ver sus ensayos, con los antiguos, con los milongueros que después fueron maestros míos, y entre esos estaba Virulazo ${ }^{1}$. Y era una particularidad en la cual mi abuelo me enseñó, que fue 
llevarme a las vías. Yo vivía allá en Morón en Villa Tesei, a 5-6 cuadras de la vía muerta, entre medio de la base militar que divide Hurlingham, Morón y Palomar. Yo estaba al cuidado de mi abuelo. Mi papá jugaba al futbol y no tenia mucho tiempo y mi mamá trabajaba a tiempo completo en un hospital. Mi abuela trabajaba también. Mi abuelo estaba [era] un vago atorrante y me llevaba a caminar ¿y como aprendí yo a caminar? ¡En las vías del tren! Nadie hoy en día me puede decir cuál era "la base" del milonguero. Yo la sé ¿Pero que pasa? Yo fui un privilegiado como muchos otros de mi generación, o antes, que tomamos ese conocimiento de cómo practicaba esta gente. Yo tenía 7- 8 años y ahí ensayaba mi abuelo, el "Virula" (Virulazo) y un montón más ¡Se hablaba del caminar! Esta gente era muy tosca para caminar entonces no les salía el ser elegantes. Usaban la elegancia desde otro lado, desde una postura que "disfrazaba" un poco el caminar. En realidad se buscaba siempre caminar plano. Y siempre era al revés del caminar en la calle. Vos tenias que pisar plano. Siempre es primero la punta, y si no míralo al Pupi ${ }^{2}$, míralo a Finito ${ }^{3}$, míralo como pisaba Aurelio Juan ${ }^{4}$ ¿Cómo pisaban? Y...jpisaban así! Así y todo había un tema de los zapatos. Todo esto me lo explicó mi abuelo. Vos nunca vas a pisar con la punta del pie levantada ¿Por qué? Antes los zapatos estaban bien lustrados, era lo mejor que tenían. "Pipi Cucú", y cuando te veía alguien de frente y vos pisabas con la punta levantada te veían la suela de los zapatos. Ya se le perdía el encanto de todo el charolado, de todo el brillo. Pises con la punta o pises con el taco siempre tiene que ser lo mas "flat" que se pueda, lo mas al piso. Entonces eso era muy importante, y después caminar linealmente.

AL: ¿Y que aprendiste en la vía?

CV: La base del tango que a mi me enseñaron era "Uno-dos-tres" y sobre la misma vía abrís y cerrás. Siempre fue siempre así. Te subías a la vía, caminabas, usabas el torso, y esto ya te ayudaba, ya tenias el paso para poder acomodarte.

AL: ¿Quedabas de costado arriba de la vía?

CV: Exacto quedabas de costado con un paso lateral ¿me entendés? Entonces eso es la motricidad que te da la comunicación con el otro. La comunicación de tu cuerpo, de tu ser, a lo que vos querés hacer con tus piernas. Todo lo que vos quieras hacer lo vas a hacer siempre y cuando estés decidido. Hoy la gente no puede hacer porque no se decide, porque piensa mucho para bailar.

AL: Vos identificaste el caminar con la espontaneidad.

CV: Exacto. El caminar de la calle siempre es como una guía, es como una base para vos y sobre ese caminar vos creás. Y siempre hubo reglas, por lo menos yo fui enseñado así. Vos que sabés de música: la salsa tiene una clave, el mambo tiene una clave [golpea dos ritmos contra la mesa].

AL: Clave de son y clave de rumba. 
$\mathrm{CV}$ : Exacto, entonces vos tenés estas cosas. Vos podés bailar los mismos pasos del tango en el tango vals. Lo que cambia va a ser como incluyas los pasos "musicalmente". Y habían reglas que eran perfectas y yo, como muchos otros, tenemos un conocimiento que después se fue perdiendo, porque los viejos se fueron muriendo todos.

AL: ¿Como ves el tango actualmente?

CV: Cambió mucho la forma de bailar y cómo se escucha la música ¿Cómo te puedo explicar? ...Yo lo voy a traer desde mi generación hasta ahora. Hoy en día se hace toda una "ensalada" de pasos y todo se enfoca en el "virtuosismo" en el quien está "mejor parado". No se como explicarlo bien, pero en mi apreciación, hoy hay mejores individualidades y antes había mejores parejas.

AL: Claudio ha sido primer bailarín de varias compañías de Tango, entre ellas de la afamada Forever Tango. Su participación en diferentes compañías le permitió conocer los cambios de los elencos a través del tiempo.

CV: Hace un tiempo estaba con Copello ${ }^{5}$ haciendo el espectáculo Rojo Tango (2012) y en un momento me acuerdo que estábamos cambiándonos y todos los pibes de la compañía hablaban "sabés que tuve una clase de Pilates, y te la recomiendo. Y yo hice una clase de Jazz y de Clásico y están muy buenas, y la verdad que la técnica que tiene esa señora está buena, me está ayudando bastante", iy todos los comentarios eran así! Un día nos cansamos un poco con el "Negro" [Copello] y les dijimos: “¿Chicos, y Tango cuándo?” ¿Me entendés lo que te digo? Hoy en día cuando se habla de técnica se habla de una técnica suprema del clásico, del jazz, como que se confunden los tantos, inconsciente o conscientemente, no lo sé.

AL: ¿'Técnicas vaciadas de Tango?

CV: ¡Claro! Vaciada de Tango. Hoy se va todo a la "estética". No se si alguna bailarina excelente que esté excedida de peso es aceptada hoy bailando. Tengo esa duda. Hoy todo es quién tiene "el tajo mas alto", "el vestido mejor". Antes lo que se buscaba era la técnica de pareja. Yo me pregunto como "miércoles" habrán hecho estos tipos [los antiguos milongueros] para aprender. Porque tienen técnica, vos les ves técnica, pero les ves "técnica de Tango". Entonces ¿qué pasó? Hubo un momento [década de los 90, s.XX] en que "la posta" la empezaron a tomar — con todo el respeto que me merecen- los folcloristas, después vinieron los del jazz, el tema de la emancipación de la mujer, el tango Queer. A partir de todo esto se empezó a "pulir el tango", por decirlo de alguna manera -te estoy hablando de mi apreciación, porque yo lo viví y vi esa transformación- y entonces se empezó todo como a "estilizar" y a ver de otra manera. A la mujer se le comienza a dar un "falso rol" en el cual se confundió el dicho de los milongueros "el tango es $50 \%$ y el $50 \%$ ", con un yo marco $50 \%$, y entonces 
ella lo interpretó como "yo agarro, yo puedo hacer". Y hay roles que en el tango son bien definidos. No puede haber dos personas para conducir un auto simultáneamente. Y si uno va a querer doblar a la derecha y el otro va a querer doblar a la izquierda ¿qué hacemos? Estas cosas comenzaron a pasar en el baile.

AL: ¿Las reglas del tango tradicional relegaron su esencia y con ello la técnica de tango?

CV: Exactamente.

AL: ¿Qué es saber pisar el tango?

CV: La forma de pisar viene de un montón de cosas. No es solamente "pisar porque pisás", jes una cosa motríz! Pero hoy, ¿qué pasa? Hoy en día cuando caminamos estamos haciendo todo diferente. Está todo como en "cajas separadas". Si vamos a hacer un boleo hacemos un boleo y si hacemos un gancho es un gancho [nombres de figuras del tango]. Y como a mi me enseñaron "todo sale de una caminada, hay un link con el mismo caminar". Y lo único que hacés cuando caminás, es caminar derecho [lineal] ipara atrás o para adelante! ¿Cuáles son las transiciones? Los giros [figura en que la mujer camina en forma circular alrededor del hombre empleando de 3 pasos]. Cuando vos terminás de girar, vas a dar siempre un paso derecho. El movimiento, como yo lo aprendí, es "capicúa" como me decía mí abuelo. Porque cuando vos caminás para adelante, siempre tu pierna va a ser lo que primero va ir y el cuerpo va acompañar. Y cuando llega "llega todo junto". Con una intención del cuerpo que tiene que ir a estar siempre arriba de tu pié. Cuando girás, tu torso dice primero "adonde va a ir" y cuando tu cuerpo "ya ve" la dirección, tu pierna va a seguir tu cuerpo. Por eso es capicúa, porque es "pierna-torso-torso-pierna". Para girar: torso-pierna. Para caminar siempre la pierna adelante. Mirá como camina "éste"...

[Claudio me muestra un video ${ }^{6}$ del Pupi, un milonguero legendario, al que se lo escucha decir "porque todo el mundo habla de cambiar el cuerpo del peso, pero nadie lo cambia. Caminar se camina normalmente (...) se tiran los pies adelante"]

CV: Pupi quiere significar que muchas veces al bailar no se está respetando la "transición del caminar". Cuando vos caminás no vas cayendo con el cuerpo. Lo que haces naturalmente es sacar el pié y el torso acompaña. Si alguien me toca la espalda, o alguien me llama, yo miro y me doy vuelta desde el torso. Es algo natural. Por ejemplo, el giro se fue desvirtuando. Lo que hoy se esta haciendo es ir a girar pivoteando [pivot: rotación del cuerpo sobre los 5 metatarsos] con el pie cruzado, en vez de hacer un giro que nace desde la posición de un caminar y desde un enrosque. El propio giro sobre la pierna de apoyo va a traer la pierna libre a enroscarse por la presión de los aductores. Ahí es donde se produce el enrosque, y no, "yo voy a llevar la pierna". El caminar te va a llevar, exactamente, naturalmen- 
te, perfectamente a la distancia que vos necesitás entre los pies. Esto es muy importante. Son cosas que mucha gente ya perdió. Hoy se enseña a pivotear nomás.

[A continuación observamos un video ${ }^{7}$ de dos legendarios milongueros, el "Chino Perico" y "La Rusa ${ }^{8}$ bailando en el Club Sunderland (Villa Urquiza 1997). ]

CV: ¿Ves? ¡Ahí pisó ella! Pisó en el tiempo ¿viste? Ahí él se frenó. Parece que él está fuera de música, ipero no! Él con el cuerpo ya está marcando el siguiente paso, que es lo que pisa ella. [marcar: proposición corporal a través del abrazo del hombre hacia a mujer, para que ella adopte una posición corporal que le permita realizar sus movimientos en términos de cuándo, en qué dirección, intensidad, articulación, ritmo y timing]. Por ejemplo, hay algunas veces que yo no estoy "cayendo" en el tiempo realmente justo. La que está cayendo en el tiempo justo es mi compañera. Y a veces muchos se fijan y dicen "Ah, estás fuera de música". Y yo digo: "No, no estoy fuera de la música porque el tiempo que yo iba a usar lo usó ella".

AL: Hay una construcción...

CV: iiExacto!!! Porque son los "dos ahî" los que están pisando. Otra cosa, vos fijate como son las sacadas que hace el Chino [situación en la que el hombre al dar un paso ocupa el espacio de la mujer y produce que la pierna libre de ella salga como-si-fuera-empujada], "cómo" son las paradas [situación en la que el hombre detiene el pie de la mujer], "dónde" pisa. Hoy veo que esta manera de entender el baile se perdió. Porque los viejos estos se fueron todos a la mierda, y te puedo asegurar que nadie toma clase con este tipo [refiriéndose al Chino Perico].

AL: ¿Como entendés la música con el cuerpo?

$\mathrm{CV}$ : Yo escucho toda la música. Yo siempre lo que estoy escuchando es esto [golpeando 4 negras]. Yo nunca estoy escuchando esto [golpea dos blancas]. Yo estoy escuchando Un-dos-tres-cuatro; cinco-seis-siete-ocho [contando en negras].

AL: Ok. vos no estás escuchando solamente los tiempos uno y tres que coinciden con el impacto de la pisada.

$\mathrm{CV}:$ ¡ NOO!

AL: ¿Escuchás lo que está en el medio?

CV: ¡Claro los medios!;Eso es lo mas importante, los medios!

AL: El dos y el cuatro.

CV: Claro ¡Olvídate! Exactamente, yo siempre los conjugo como pares [a los tiempos]. Otra cosa es que cuando vos bailás "cuando un milonguero pisa no crece más el pasto". Uno va, "KA-tim, KA-tim, KA-tan, KA-chan, TA-ta, TA" [ritmo de negra], pero uno hace como un cosa "en el medio" ¿Por qué? Porque 
vos tenés que respetar la guía del caminar. Hoy en día se va "lineal y directo y no se pasa por casa y después se sale".

AL: Lineal y directo es ¿isin sentir el medio?

CV: Claaaaroo.

AL: El traslado corporal pierde la relación fuerte débil de la música.

CV: Exacto, exacto.

AL: Fuerte, débil.

CV: Fuerte débil, exacto. TAN-pum-TAN-pum [ritmo de negra]. Otra cosa, nadie "mastica el piso" al pisar como nos enseñaban los milongueros antes PAApa-pa-PA-y-sa, LÍ! [negra-2 corcheas-negra-2 corcheas-negra], PA-ti-ki-KA-tim [negra-2 corcheas-2 negras]. Esto es toda la herencia que yo tengo de todos estos milongueros. El tema es que vos "pises con propiedad en la música" y "decir exactamente lo que la música quiere decir". Hay otra cosa que se confunde. Una cosa es marcar la música con los pies [aquí marcar es poner énfasis en los apoyos] y otra cosa es caminar al ritmo de la música. Porque el marcar con los pies no significa que vos estés bailando bien el ritmo. Hay que entender que cuando bailás son cuatro "patas" y tenés que sincronizar esas cuatro patas. Vos tenés que ser artífice de un movimiento en el cual vos tenés que crear lo que tiene que hacer la mujer y cómo vos querés hacer tu parte. Y todo para mi es música y es marcato ${ }^{9}$. Por ejemplo mientras la mujer hace: un, dos [ritmo negra-negra], vos hacés: undos, tres [dos corcheas-negra]. Todo esto tengo que tenerlo bien afilado para poder "marcar y entrar" y esas cosas, a veces, ya no las veo. Todo es una cuestión de intención. El cuerpo es una intención. Todo el tiempo. El cuerpo está intencionado a hacer algo, a proponer y a ejecutar. El cuerpo lo que hace es propone y después ejecuta. ¡Las piernas ejecutan! Pero también el cuerpo, el abrazo. Otra cosa que quiero decir. Antes las paradas eran "falsas" paradas, era como si fuera una parada y después marcabas lo que le dicen el medio giro. Pero después cuando las mujeres -y vuelvo atrás en lo que te decía- empezaron con el 50\% y 50\%, apenas vos les tocás de atrás el pie en la parte de afuera ella ya piensa que es una parada. Entonces de ahí se empezó a desvirtuar lo que hacían los antiguos milongueros y se inventó el pisar por adentro de la mujer. Antes la mujer entendía la falsa parada porque ella "seguía una marca desde arriba" y no porque le paraba el pie. Son medias complejas las cosas. El Chino pisa siempre en el eje. Porque está el eje tuyo, el eje de ella y el eje de los dos. Y este es el mas importante.

AL: Para que funcione la comunicación.

CV: Exactamente. A mi me tocó ver clases para saloneros ${ }^{10}$ en todos los lados a los que yo fui. Hay cosas que yo veo cuando ellos pisan y entonces les digo "¿Por qué están pisando afuera [del eje] de la mujer? ¿Porque no hacen un medio giro 
bien y en la mujer? ¿Por qué no buscan la manera de acomodar a la mujer, en vez de acomodarse ustedes solos y dejarla a la mujer "que se arregle"? Esa comunicación que tiene que existir, no pasa hoy. Para bailar bien, vos tenés que comunicar bien [aquí sinónimo de marcar]. Si vos comunicas bien la mujer va a recibir bien. Si la mujer no recibe bien no puede, porque es difícil realmente seguir bien. ¿Quienes son los que marcan bien? Los que saben "hacer de mujer" perfectamente ¡Nunca van a ser mujer, pero saben los "jeites" de la mujer! ¿Porque los milongueros eran buenos marcando? Porque sabían el paso de la mujer. Por eso practicaban entre hombres.

AL: Hablame del peso del cuerpo...

$\mathrm{CV}$ : Yo trabajo mucho con los cambios de dinámica. Desde mi apreciación siempre hablando en esos términos - una cosa es bailar, cantar y otra cosa es interpretar. Yo siempre digo, que antes de bailar siempre estoy pensando que estoy a punto de hacer mi mejor obra de arte. Yo entro en un laberinto y yo me entro a hacer un quilombo y tratar de resolver ese quilombo. Tengo que entrar en un laberinto y buscar siempre la salida. Y un paso, un movimiento me va trayendo el otro. Esa es la manera que yo pienso y que me enseñaron a hacer. Yo "siento cada cosa que estoy haciendo con mi pareja”. Este es el tema de la comunicación. Esta es la riqueza... Hoy el cambio de dinámica casi no existe.

AL: Contame un poco más de la marca.

CV: Cuando yo entraba al viejo Almagro o iba a Atlanta y vos agarrabas una mujer ¿qué es lo que hacías primero? Antes teníamos la costumbre esta [mientras muestra un pequeño movimiento de rotación longitudinal izquierda derecha de su torso en situación de abrazo], siempre era así, fijate, preguntále a cualquiera. Hacíamos eso y ella no se movía. Entonces ahí "aflojabas" un poco los torsos para saber que es lo que ibas a hacer. Entonces, ¿que es lo que hacía la mujer "antes"? Antes ella iba hasta donde se sentía segura de que lo que iba a hacer. Hoy "esturnudás” y la mujer ya se mueve. Es más, se movió y te metió dos adornos, no uno. Amén. Perfecto. Todo bien. Pero no es lo que yo quería. Cuando yo estoy parado doy una primera intención a la mujer, y después hay una segunda intención. La primera es "vamos a movernos", la segunda es "nos movemos". Hay dos intensiones del torso. No es solamente "¡ah! vamos a movernos", es "cuándo y cómo". ¿Cuál es el artífice del movimiento de lo que estamos hablando? ¿Con qué articulamos, con qué hablamos, la comunicación dónde nace? iiisiempre con la parte de arriba!!! La parte de abajo es una consecuencia de lo que nosotros estamos haciendo arriba. Si queremos ir a un lado. El cuerpo propone y va. El cuerpo acciona, "el torso es el alma de las piernas". Agarrá una bandera. Si la movés del palo la bandera viene. Pero la bandera viene en delay. Por eso los movimientos tienen que ser en contraposición siempre. Porque si bailás de esa manera, tenés el tiempo. ¿Por 
qué? Es como el juego de ajedrez, en donde el tipo está creando y elaborando tres-cuatro movimientos adelante. La mujer tiene una "pierna en el presente y una pierna en el futuro". El hombre también. Pero yo ya sé el futuro y para la mujer el futuro es una incertidumbre. Entonces la mujer debe vivir el presente ¿Entendés lo que te quiero decir? Yo no puedo dudar, yo tengo que ir saliendo más o menos como una víbora — por decirte la fluidez — de llevarla a ella acá, allá. Mucho de lo que bailo no es coreografía, es todo improvisado, es lo que sale en el momento. Obviamente, vos lo vas a ver repetido en varios tangos porque cada uno crea su propio patrón de baile, su propia cadencia. Que es también una palabra muy difícil de entender.

AL: ¿Qué entendés por cadencia?

CV: Cadencia es la forma en que vos elaborás el movimiento. Cadencia es algo que no se enseña. Alguien que me diga que enseña una cadencia...jOlvídate!

\section{AL: ¿Cadencia?}

CV: Es la forma que vos le das a un movimiento. Tiene que ver con todo. Vos, ¿por qué sos elegante? ¿Qué es algo cadencioso? Es "algo que fluye de una forma especial". Es algo abstracto. Se ve pero parece que no existe. Es la forma que vos manejás tu cuerpo. Esa es la cadencia. Por ejemplo, en Brasil le dicen mucho el ginga, si el samba no tiene ginga no pasa nada. Esto es muy importante. Pero te estaba diciendo: jel delay! Esto es lo que va a provocar el torso, que es adonde los dos cuerpos se comunican, y abajo va a ser la consecuencia de esa comunicación. Si hay buena comunicación ahí arriba, abajo va a bajar todo bien. ¿Por qué? Yo necesito que la mujer venga con el "pie atrás" Porque es la manera que yo puedo generar un montón de cosas. Si la mujer ya se me adelantó y me vino al pie...ya no puedo generar....

AL: A la pregunta de cómo ve hoy la enseñanza, Claudio responde que actualmente las secuencias se explican separando los movimientos del hombre y la mujer. Entonces la mujer ya se mueve por una coreografía que aprendió. Y como "ella ya sabe lo que él sabe", esto va en desmedro de que haya buenos lideres.

CV: Por experiencia vos te das cuenta si el tipo "le está marcando o no le está marcando a la mujer". Actualmente hay parejas que sincronizan muy bien, aunque "una cosa es sincronizar y otra cosa es seguir y llevar".

AL: ¿En que consiste esa diferencia?

CV: Se va a perder la fluidez del paso. No se va a ver una comunicación, se va a ver una sincronización de ambos. Una cosa es sincronizar porque uno conduce y el otro sigue y otra es sincronizar porque hacen de memoria. Otra cosa. El abrazo es contacto y antes ¿que te decían los tipos? "loco, el tango se transmite de piel a 
piel" ¡Contacto! (golpeando fuerte sus manos). Y hoy se sincroniza mucho, porque no hay ese contacto.

AL: ¿Qué se perdió del caminar de los viejos milongueros?

$\mathrm{CV}$ : Ja! Me ponés en un aprieto. Desde mi sensibilidad, hoy en día caminar es una cosa técnica, mas de jazz, de baile muy de puntita de pie, y el caminar de los viejos milongueros es un caminar "mas genuino, con mas peso, mas densidad", que es lo que nos falta hoy. Y si vos ves, hoy cada bailarín es una copia del otro, todos se paran igual, todos agarran a la mina igual, de la misma manera.

AL: Tocaste el tema densidad...

CV: Densidad es el peso que vos le ponés a tu caminar, como vos trasladas el cuerpo, qué tanto peso le ponés. Cuando yo piso la densidad es la manera en que yo coloco arriba del pie el cuerpo y la pierna. Es como vos colocás el cuerpo y le ponés el empeño y eso tiene que ver con una "intención”. Además, un tema importante es cómo se trabaja el pie libre. Si el pie libre viene con más delay va a tener más densidad, si el pie libre viene mucho mas rápido al eje [menos delay], quiere decir que se está necesitando estar en el eje por una cuestión de no poder transferir el peso correctamente.

AL: Justamente en un trabajo anterior yo identificaba que los viejos milongueros mantenían los pies apoyados al trasladar el peso y entonces la pierna libre del milonguero tenia mas tiempo para expresarse, como vos decís viene con delay ii Ahora me cerró la idea!!

CV: Jaaaaaa! Cuando vos pasas el peso hacia delante la pierna libre tiene que estar estirada, y cuando vos vas atrás tiene que ser exactamente lo mismo. La densidad tiene que ver con la alineación del cuerpo en relación a la pierna estirada. Como me decías antes vos, y para ser mas explícito, los pies duran más tiempo apoyados en el piso. Esa es la explicación válida. La diferencia está entre cuando un tipo "usa" las dos piernas para caminar y cuando realmente "usa" una. En términos de diferencia, cuando vos querés ser mas denso es cuando realmente vos tenés que manejar mas los pies. Otra cosa que te quería decir que hoy lo veo mucho - especialmente cuando las minas y los tipos caminan adelante- creen que pasan el peso del cuerpo y no lo pasan. Para caminar tengo que llevar esa guía de la que vengo hablando. Si vos caminás hacia delante y hacés esto que hacen muchos [mostrándome un paso en el que apoya el pie con la pierna flexionada, quedándole el pecho inclinado adelante y la cadera hacia atrás].

AL: ¡Ahí no pasaste el peso!

$\mathrm{CV}$ : ¿Por qué no pasó el peso?

AL: Porque el cuerpo está desalineado (muy inclinado) con respecto al pie de apoyo. 
CV: Y si yo te digo que vos estires la pierna de adelante ¿Qué pasa con el cuerpo?

AL: Bueno, el peso y el eje longitudinal del cuerpo se enderezan y se van para atrás. Das un paso adelante pero "no" tengo el peso bien sobre el pie de apoyo.

CV: ¡Exactamente! Vos llevaste el cuerpo adelante pero "tu peso no está adelante". Eso es muy importante. Tu cuerpo siempre tiene que estar encima de tus piernas y, siempre estás en transición, en una pierna o en otra. Por ejemplo, si yo "hago de mujer" y me marcan un ocho, yo tengo que hacerlo desde el caminar [ocho: figura muy empleada por la mujer que consiste en caminar cambiando de sentido reproduciendo una "S" alrededor del varón. Al hacer dos S invertidas, una respecto de la otra, se forma el ocho en el piso]. Una vez que terminás de caminar, para decírtelo mas específico, voy a empezar a seguir a mi varón para ver qué es lo que quiere y ahí estoy apto para poder flexionar. No antes, ¿̇me entendés? Entonces una vez que él va, yo sigo y, todo esto me va trayendo en espirales abajo. Esto es muy importante. Para mi todo es muy profundo. Primero yo aprendí de los viejos, pero yo también creé mi propia doctrina y también como vos investigás, yo también investigo. Me tomé tiempo para poder enseñar y saber.

\section{Conclusiones}

La entrevista presentó un valioso testimonio en el que Villagra describe aspectos menos conocidos del TT y muestra que los viejos milongueros entendían el baile como una globalidad corporal entre la emoción que les producía la música y la motricidad del caminar como "guía" común de todas las figuras del tango. Villagra rescata dos momentos de esta guía, el cambio de peso que se produce al dar paso y el delay de la pierna libre que parte estirada hacia la pierna de base. Se trata de dos instancias esenciales del sentir corporal que espejan la relación fuertedébil del marcato de la música de Tango y organizan la comunicación de la pareja en las instancias de "proponer y ejecutar" (dos instancias que a su vez son parte de la guía del caminar). Esta forma de hacer y de comunicar tan especial se fue perdiendo con la muerte de los antiguos milongueros. Las nuevas generaciones al profesionalizar el Tango incluyeron en el "menú" de su aprendizaje otras técnicas de danza que los llevaron a "pulir" el movimiento, creando una estética que "deformó" la técnica del TT. Además, la estructura comunicacional del proponer y ejecutar se fue desdibujando hacia una comunicación basada en una sincronización de movimientos, y exacerbando la técnica individual, en detrimento de la técnica de pareja. 


\section{Notas}

1. Jorge Martín Orcaizaguirre. Haedo. Buenos Aires (1926-1990).

2. Ernesto Norberto Castelo. Buenos Aires (1936-2007).

3. Ramón Rivera (1929-1987).

4. Juan Aurelio "Nito" García. Bragado, Buenos Aires (1936-).

5. Carlos Copello (Santiago del Estero)

6. https://www.youtube.com/watch?v=QtUKf_xOswM

7. https: / www.youtube.com/watch?v=Eyj2D54_O2o\&t=40s

8. Ricardo Ponce (San Luis, 1931) y Juana Lemos (s/d).

9. Uno de los estilos de marcación de la música de tango en el que son tocados los cuatro tiempos del compás en una articulación generalmente staccato.

10. Estilo de tango que se bailaba en los barrios de Villa Urquiza y Saavedra.

\section{Financiamiento}

Alejandro Grosso Laguna es financiado por fondos europeos a través de una beca posdoctoral de la Fundação para a Ciência e a Tecnologia (FCT) Portugal.

\section{Agradecimientos}

Dra Marina Rieznik. Investigadora Adjunta Conicet. UBA-UNQ

\section{Acerca del autor}

\section{Alejandro César Grosso Laguna}

cultura@netcabo.pt

Bailarín, profesor de tango y músico especializado en danza. Estudió Educación Musical y Guitarra en el Conservatorio Superior de Música Manuel de Falla y en la Universidad de La Plata (FBA-UNLP). Doctorado por la Universidad de Évora, Portugal. Tema "Revisión de problemas comunicacionales en el contexto de clases de técnica de danza desde la perspectiva de un músico de danza”. Ganó una beca de doctorado (2008) (FCT). Desde 2015 es 
investigador posdoctorado con beca de la FCT. Tema "Aspectos de la comunicación en la performance expresiva multimodal: Problemas de cruzamiento entre contenidos proposicionales y no proposicionales". Posee formación dancística y en el sistema Gyrotonic Expanded System. Investigador del Laboratorio para el estudio de la Experiencia Musical (UNLP) y el Instituto de Etnomusicologia- Centro de Estudos em Música e Dança, Universidad de Aveiro, Portugal.Creador de la Milonga d'A Barraca (1999, Lisboa) acreditada como una de las mas antiguas y tradicionales de Europa. Ha llevado la música de Lisboa al seno de la milonga d'A Barraca y promovido una interpretación del Fado a partir de los movimientos de pareja del Tango. 